\title{
Optimizing a microwave gas ion source for continuous-flow accelerator mass spectrometry (CFAMS) ${ }^{\text {a) }}$
}

\author{
K. F. von Reden ${ }^{1, b)}$, M. L. Roberts ${ }^{1)}$, J. R. Burton ${ }^{1)}$, and S. R. Beaupré ${ }^{1)}$ \\ ${ }^{1}$ Geology \& Geophysics Department, Woods Hole Oceanographic Institution (WHOI), \\ Woods Hole, MA 02543, USA
}

\begin{abstract}
A $2.45 \mathrm{GHz}$ microwave ion source coupled with a magnesium charge exchange canal $(\mathrm{CxC})$ has been successfully adapted to a large acceptance radiocarbon accelerator mass spectrometry system at the National Ocean Sciences AMS Facility (NOSAMS), Woods Hole Oceanographic Institution. $\mathrm{CO}_{2}$ samples from various preparation sources are injected into the source through a glass capillary at $370 \mu \mathrm{l} / \mathrm{min}$. Routine system parameters are about 120 - $140 \mu \mathrm{A}$ of negative ${ }^{12} \mathrm{C}$ current after the $\mathrm{CxC}$, leading to about $400{ }^{14} \mathrm{C}$ counts per second for a modern sample and implying a system efficiency of $0.2 \%$. While these parameters already allow us to perform high quality AMS analyses on large samples, we are working on ways to improve the output of the ion source regarding emittance and efficiency. Modeling calculations suggest modifications in the extraction triode geometry, shape and size of the plasma chamber could improve emittance and hence ion transport efficiency. Results of experimental tests of these modifications are presented.
\end{abstract}

\section{INTRODUCTION}

a) Contributed paper, published as part of the Proceedings of the $14^{\text {th }}$ International Conference on Ion Sources, Giardini-Naxos, Italy, September 2011.

b) Author to whom correspondence should be addressed. Electronic mail: kvonreden@whoi.edu. 
Since its breakthrough in the late 1970s, accelerator mass spectrometry (AMS) with tandem accelerators has seen a dramatic increase in applications with emphasis on radiocarbon. Developments on all aspects of AMS systems have led to compact designs as an alternative to the large systems that required experimental halls or separate laboratory buildings. Even low-energy charge exchange systems and systems exploiting laser resonance spectroscopy that do not make use of tandem accelerators are now in operation, but these have not yet reached the performance level of the most advanced tandem facilities. Independent of the type of AMS system, the majority of all developments still rely on an ion source capable of producing negative ions at levels conducive to high precision mass ratio analysis. Various forms of the Middleton-style hemispherical ionizer cesium sputter ion source have been particularly successful, requiring solid carbon samples as sputter targets. The most advanced of these sources are highly efficient with negative ion yields of about $25 \%$ of a sample's carbon content ${ }^{1-3}$. Hybrid versions of the sputter source have been in use at several labs that allow "sputtering" of $\mathrm{CO}_{2}$ from titanium frits at lower ion yields. As an alternative, the NOSAMS Facility has been conducting a multi-year project of developing a $2.45 \mathrm{GHz}$ microwave ion source that allows direct injection and analysis of $\mathrm{CO}_{2}$ gas, by dissociation and ionization in the gas phase. The unique feature of this source is that it provides the ability to analyze continually varying streams of $\mathrm{CO} 2$ from sources like gas or liquid chromatography.

\section{DEVELOPMENT PHASE I}

The original source was comprised of a Chalk River Laboratory compact microwave ion source ${ }^{4}$ coupled to a magnesium charge exchange canal. Descriptions of these earlier efforts can be found elsewhere ${ }^{5-8}$. On the original (prototype) source the permanent magnet solenoid allowed for a simple setup of the ion source deck, but the extraction triode design had mechanical shortcomings that proved detrimental to the operation of the source as part of an AMS injector. The plasma chamber, acceleration, 
and electron suppression (“decel”) electrodes were integrated into a reentrant design, held together by poly vinyl acetate glue joints between the support plates and the ceramic isolation tubes. Mechanical stress, especially during maintenance, led to occasional vacuum failures of the assembly. In addition, water cooling channels were connected via o-ring seals between the support plates and prone to leaking. As a consequence, the source tended to spark frequently and could never be consistently operated at extraction voltages over $25 \mathrm{kV}$, considerably below the optimal voltage for a $5 \mathrm{~mm}$ plasma aperture diameter. Even so, the results we obtained during tests of this source gave us valuable information for a redesign that is now the basis of our current ion source. Table I summarizes the operational parameters for near optimal test stand conditions in comparison with those for our present source. Between the parameter sets lie several years of development that will be retraced in the following section.

TABLE I. Operational parameters for the microwave gas ion sources at NOSAMS.

\begin{tabular}{|c|c|c|}
\hline & Prototype Source & Present Source (CFAMS) \\
\hline Extraction Supply Voltage (Current) & $<30 \mathrm{kV}(\sim 8 \mathrm{~mA})$ & $40 \mathrm{kV}(\sim 7 \mathrm{~mA})$ \\
\hline Suppression Voltage (Current) & $-1.4 \mathrm{kV}(\sim 1.5 \mathrm{~mA})$ & $-3.3 \mathrm{kV}(\sim 0.3 \mathrm{~mA})$ \\
\hline RF (Power) & $2.45 \mathrm{GHz}(180 \mathrm{~W})$ & $2.45 \mathrm{GHZ}(260 \mathrm{~W})$ \\
\hline Solenoid Field & $\sim 0.09 \mathrm{~T}$ & $0.096 \mathrm{~T}$ \\
\hline $\mathrm{CO}_{2}$ Flow Rate & $\sim 0.2 \mathrm{ml} / \mathrm{min}$ & $0.37 \mathrm{ml} / \mathrm{min}$ \\
\hline Laboratory Emittance (100\% of beam) & $60-80 \pi \mathrm{mm} \mathrm{mrad}$ & $60 \pi \mathrm{mm} \mathrm{mrad}$ \\
\hline${ }^{12} \mathrm{C}^{+}$Current & $0.6-1 \mathrm{~mA}$ & $\mathrm{n} / \mathrm{a}^{\mathrm{a}}$ \\
\hline${ }^{12} \mathrm{C}^{-}$Current (after CxC) & $50-80 \mu \mathrm{A}$ & $\sim 140 \mu \mathrm{A}$ \\
\hline${ }^{12} \mathrm{C}^{+}$Current (after accelerator) & $\mathrm{n} / \mathrm{a}^{\mathrm{b}}$ & $\sim 42 \mu \mathrm{A}$ \\
\hline${ }^{14} \mathrm{C}$ Count Rate (from modern sample) & $\mathrm{n} / \mathrm{a}^{\mathrm{b}}$ & $\sim 400 / \mathrm{s}$ \\
\hline
\end{tabular}

${ }^{\mathrm{a}}$ Positive currents cannot be analyzed with our system.

${ }^{\mathrm{b}}$ The prototype source was never connected to the CFAMS system. 


\section{DEVELOPMENT PHASE II}

As a consequence of the prototype ion source test results we decided to design and build a new large acceptance AMS system, capable of analyzing the large beams extracted from a microwave ion source $^{9}$. At the same time we redesigned the ion source in collaboration with the Chalk River group, aiming to improve several aspects of the prototype source ${ }^{10}$. While the permanent magnet solenoid was an elegant space saving solution, we instead opted for a set of three solenoid coils to give us control over the axial magnetic B field distribution and intensity. In the new design the $\mathrm{CxC}$ was moved closer to the extraction apertures in order to maximize transmission through the canal. The extraction electrode assembly was decoupled from the plasma chamber and connected to the $\mathrm{CxC}$ in an attempt to create a new mode of operation: plasma chamber and ion source body at ground potential, $\mathrm{CxC}$ at $-30 \mathrm{kV}$ (suppressor at $-32 \mathrm{kV}$ ). This mode would allow generating $60 \mathrm{keV}$ beams via the charge exchange process and should result in better transmission through our AMS system. However, as designed and built, the alignment and electrical field management of the assembly proved too difficult for routine operation. We reverted to a setup that kept the plasma chamber at an elevated potential ( $+40 \mathrm{kV})$ and the $\mathrm{CxC}$ at ground, and mounted the extraction assembly into the exit flange of the ion source body, separate from the $\mathrm{CxC}$ (only connected through cooling lines). Although improved, alignment of the plasma aperture with respect to the extraction apertures is still a delicate procedure, as it requires shimming and therefore cannot be done with the source in operation. Modifications are underway to allow adjusting the position of the plasma chamber while the source is running and using the Faraday cup readings throughout the AMS system for optimization.

\section{SOURCE EMITTANCE}

In recent papers we described the performance of the CFAMS system ${ }^{11,12}$. Given the emittance of the source, established both in modeling and in experiment, we came to the conclusion that the 
stripper canal of the accelerator was the limiting device in the system. From Table I it can be inferred that the transmission through the accelerator is $30 \%$, compared to about $41 \%$ for a beam from an MCSNICS sputter ion source operated on the same system. To ensure that we had done everything reasonable to optimize the ion source parameters, we revisited our earlier modeling calculations attempting to reduce the emittance without losing too much of the beam intensity and hoping to gain a net increase in ion efficiency.

\section{A. Modeling}

In our design studies for the optimal extraction we have employed the numerical ion source modeling program PBGUNS 5.04 ${ }^{13}$. The original model results matched the output of our prototype and

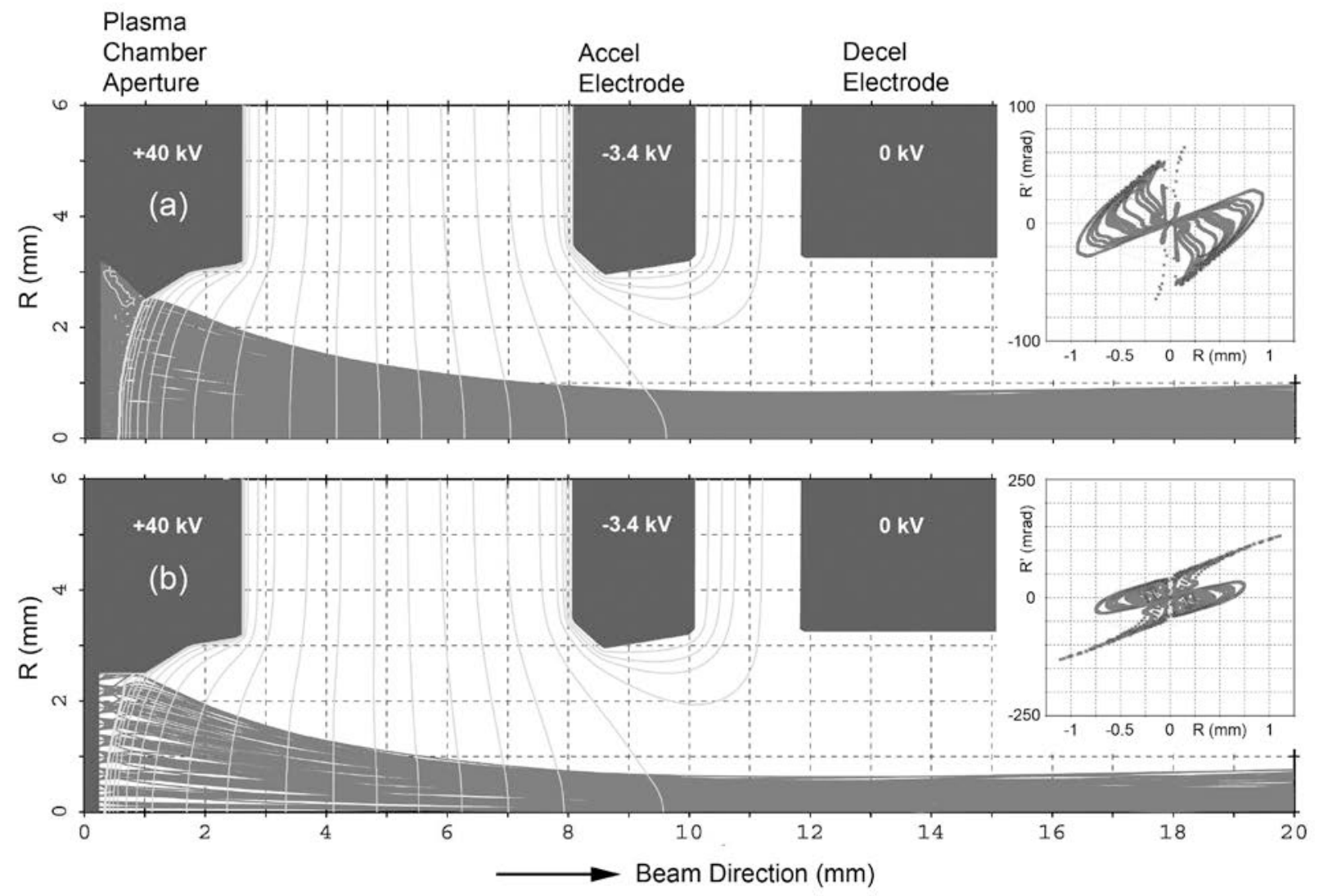

FIG. 1. PBGUNS calculations for the original plasma aperture (a) and for the modified aperture (b). Cylindrical symmetry about the $\mathrm{x}$-axis is assumed, the vertical axis denoting the radius $\mathrm{R}$ of the assembly.About 30,000 particle rays are calculated (not all drawn) for five mass species $\left(10 \% \mathrm{C}^{+}, 13 \% \mathrm{O}^{+}, 17 \% \mathrm{O}_{2}^{+}, 50 \% \mathrm{CO}^{+}, 10 \%\right.$ $\mathrm{CO}_{2}{ }^{+}$). The inserts on the right represent the lateral emittance plotted at $19 \mathrm{~mm}$ distance from the plasma aperture. Not shown in the figure is the slightlv decreasing (left to right) toroidal magnet field strength of 0.96T. 
redesigned ion sources quite well, and a study comparing PBGUNS and IGUN ${ }^{14}$ for a similar triode system ${ }^{15}$ confirmed that both codes can be used to predict the experimental data equally well. From experience with the prototype ion source we know that a reduction of the plasma aperture diameter reduces the extractable current without lowering the emittance significantly. We therefore concentrated on the shape of the $5 \mathrm{~mm}$ diameter aperture aiming to reduce the maximum angle with which the ions could enter the extraction gap (Fig. 1a), essentially increasing the thickness of the plasma aperture to

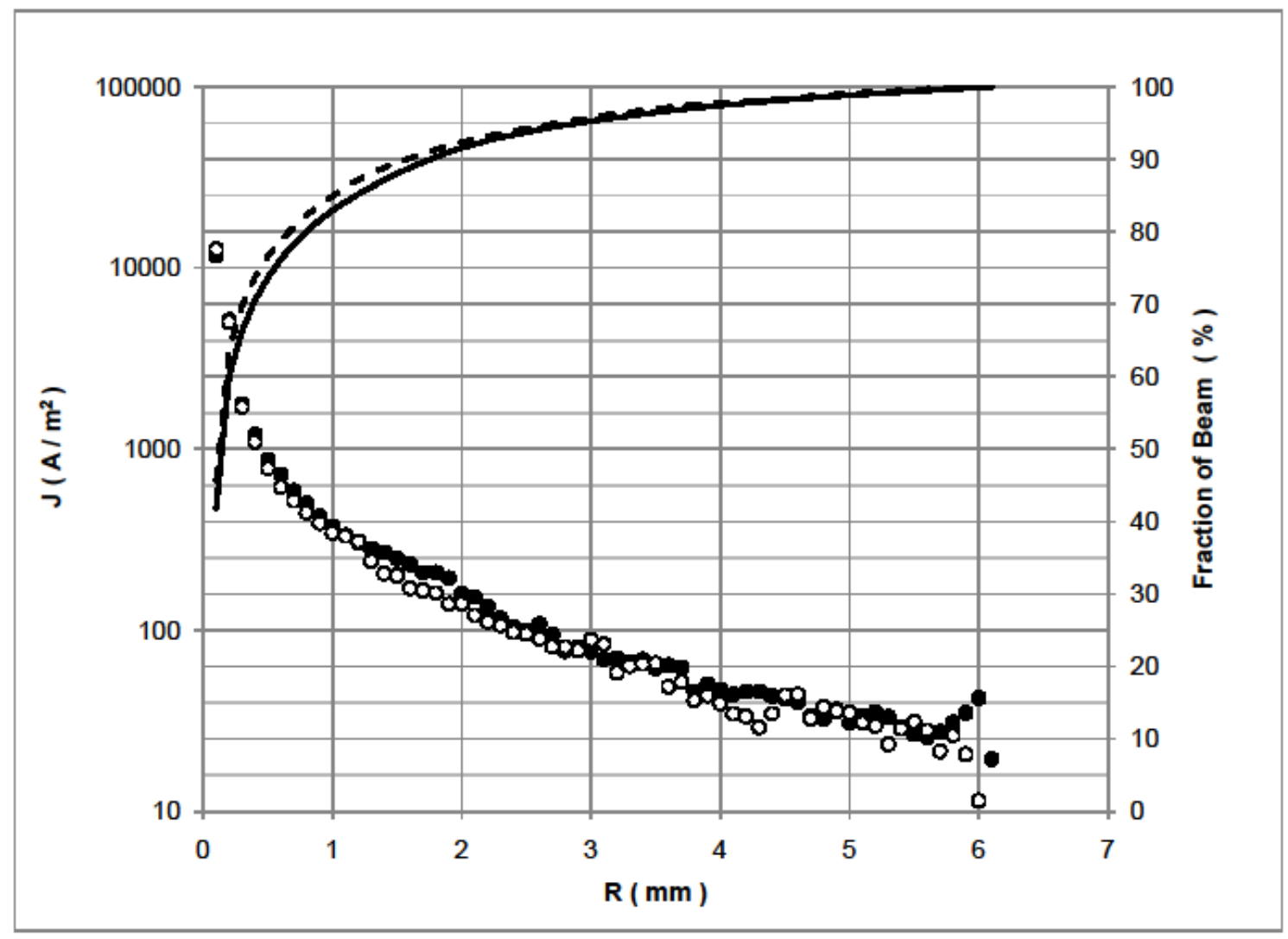

FIG. 2. Calculated current density of the extracted positive ions as a function of the beam radius R, extrapolated to a point $300 \mathrm{~mm}$ downstream from the plasma aperture on a logarithmic scale (filled circles: original geometry, open circles: modified geometry). The solid and dashed lines depict the fraction of the beams as function of $\mathrm{R}$ for the original and modified geometry (linear scale, right hand axis). 
form an extraction tube (Fig. 1b). This was expected to lead to a reduction in current ${ }^{15}$, while also altering the emittance (see inserts in fig. 1). In the modified version the core of the ion beam occupies a smaller lateral phase space than it does in the original geometry. However, a long tail exceeding $50 \mathrm{mrad}$ half angle leads to the loss of about $4 \%$ of the beam already in the extraction regime. Figure 2 shows the current density extrapolated to $300 \mathrm{~mm}$ downstream of the plasma aperture, the location of the exit of the CxC. Both calculations predict $95 \%$ of the beam to be within a radius of less than $3 \mathrm{~mm}$, but the modified version distribution appears to be slightly narrower at that point. The two cases assume the magnetic field to be identical in the extraction region, a condition that is experimentally difficult to ensure. Small changes in the alignment of the extraction system or solenoid coil current could affect the divergence of the extracted ions when leaving the field region. Fully understanding that the chances for a net improvement of the ion efficiency due to this modification would probably be small, we made the alteration to the plasma chamber for an experimental test.

\section{B. Experimental test}

Lacking better scanning devices we checked the beam distribution at the $300 \mathrm{~mm}$ point by inserting a steel plate for a brief exposure to the extracted beam. The burn marks on the plate from the two configurations of the plasma aperture agreed well with the calculated distributions, but visual inspection of the plates after exposure revealed that the intensity of the extracted beam from the modified aperture was much lower than that from the original version. However, the important question was whether there was an improvement in transmission through the system for the modified geometry. Table II compares the measured Faraday cup readings for the two configurations together with the transmission information. Clearly, the numbers are disappointing, showing that rather than achieving an

improvement in transmission it dropped slightly, while the ${ }^{12} \mathrm{C}$ current from the modified aperture is reduced to about $20 \%$ of the value obtained with the original geometry. 
TABLE II. Comparison of beam transmission between original and modified plasma aperture.

\begin{tabular}{|c|c|c|}
\hline & Original Aperture & Modified Aperture \\
\hline${ }^{12} \mathrm{C}^{-}$in off-axis FC (low-energy end) & $115 \mu \mathrm{A}$ & $24 \mu \mathrm{A}$ \\
\hline${ }^{12} \mathrm{C}^{+}$in high-energy FC & $35 \mu \mathrm{A}$ & $6.8 \mu \mathrm{A}$ \\
\hline Transmission & $30 \%$ & $28 \%$ \\
\hline
\end{tabular}

\section{DISCUSSION}

Our understanding of the operation of our microwave ion source has allowed us to set up continuous-flow injection methods for AMS analysis in both experimental and even semi-routine arrangements. Given the requirements of providing analytical AMS services to a sizeable ocean sciences user community, the NOSAMS facility has to manage resources (including time) for development of the AMS ion sources carefully, with minimal disruption of the routine operation. Experiments like the one described in this paper have to be designed without major reconfiguration of the system. Such in-situ improvement attempts have a relatively low rate of success, but will give us feedback on the further direction of our development. In this case, it is apparent that long years of experimentation, starting at Chalk River Labs, have led to a plasma aperture geometry that cannot be improved easily. Interfering with the plasma volume geometry near the aperture severely reduces the ion flow to the aperture, while the emittance of the extracted beam is only slightly affected for a given aperture diameter. As an aside, lowering the volume of the cylindrical plasma chamber by reducing the diameter from $50 \mathrm{~mm}$ to $25 \mathrm{~mm}$ had no discernable effect on the extracted beam, making it possible to design much more compact AMS 
microwave gas ion sources in the future. Concerning system ion efficiency, using the data from table I we can calculate the maximum achievable value (assuming we have reached the optimum ion source efficiency with our original extraction optics): present efficiency (0.2\%) times the ratio of the sputter source beam transmission (41\%) over the present routine gas source beam transmission (29\%), yielding $0.28 \%$ theoretically achievable efficiency. While that may not seem to be a significant increase, it would make a difference for AMS by allowing us to analyze smaller samples than we can now, or to reduce the necessary time to achieve a targeted ${ }^{14} \mathrm{C}$ count for a given sample by $30 \%$.

\section{CONCLUSIONS AND OUTLOOK}

The performance of our microwave gas ion source has reached levels that will be difficult to improve by changing the plasma side of the extraction triode. Possible further development of the ion source could include implementing a remotely operable sled design that would allow changing the extraction gap size during operation for beam optimization, along the line described in ${ }^{16}$. However, the approach most likely to provide immediate improvement is to enlarge the acceptance of the AMS system by increasing the cross section of the terminal stripper canal in the tandem accelerator. At this point we already have a continuous-flow AMS system operating at high level. Most recently, the stability and consistency of the gas ion source was put to a large scale test by analyzing a batch of nearly 500 coral carbonate samples in a "manual" gas bench setup for a reconnaissance survey. With automation we expect this type of project to be accomplished in less than two weeks (compared to more than four weeks in a traditional routine AMS operation). Other type of gas injection methods are also under development, aiming at utilizing the true capability of a microwave gas ion source: analyzing rapid succession of sample gas pulses as they occur in chromatographic applications. First tests of such true continuous-flow applications have already shown good promise ${ }^{11}$. 


\section{ACKNOWLEDGMENT}

This work has been supported by the US National Science Foundation through Cooperative Agreement OCE-0753487.

\section{REFERENCES}

${ }^{1}$ T. A. Brown, M. L. Roberts and J. R. Southon, Nucl. Instrum. and Methods in Phys. Res. B 172, 344 (2000).

${ }^{2}$ J. R. Southon and G. M. Santos, Nucl. Instrum. and Methods in Phys. Res. B 259, 88 (2007).

${ }^{3}$ M. L. Roberts, J. R. Burton, K. L. Elder, B. E. Longworth, C. P. McIntyre, K. F. von Reden, B. X. Han, B. E. Rosenheim, W. J. Jenkins, E. Galutschek, A. P. McNichol, Radiocarbon 52, 228 (2010).

${ }^{4}$ J. S. C. Wills, R. A. Lewis, J. Diserens, H. Schmeing, and T. Taylor, Rev. Sci. Instrum. 69, 65 (1998).

${ }^{5}$ R. J. Schneider, K.F. von Reden a, J.S.C. Wills, W.T. Diamond, R. Lewis, G. Savard, H. Schmeing, Nucl. Instrum. and Methods in Phys. Res. B 123, 546 (1997). (1998).

${ }^{6}$ R. J. Schneider, J. M. Hayes, K. F. von Reden, A. P. McNichol, T. I. Eglinton, Radiocarbon 40, 95

${ }^{7}$ R. J. Schneider, K.F. von Reden, J.M. Hayes, J.S.C. Wills, W.G.E. Kern, S.-W. Kim, Nucl. Instrum. and Methods in Phys. Res. B 172, 252 (2000).

${ }^{8}$ S-W Kim, R. J. Schneider, K. F. von Reden, and J. M. Hayes, and J. S. C. Wills, Rev.Sci.Instrum. 73, 846 (2002).

${ }^{9}$ B. X. Han, K.F. von Reden, M.L. Roberts, R.J. Schneider, J.M. Hayes, W.J. Jenkins, Nucl. Instrum. and Methods in Phys. Res. B 259, 111 (2007).

${ }^{10}$ M. L. Roberts, R.J. Schneider, K.F. von Reden, J.S.C. Wills, B.X. Han, J.M. Hayes, B.E. Rosenheim, W.J. Jenkins, Nucl. Instrum. and Methods in Phys. Res. B 259, 83 (2007). 
${ }^{11}$ M. L. Roberts, K.F. von Reden, C.P. McIntyre, J.R. Burton, Nucl. Instrum. and Methods in Phys. Res. B (2011), in press, doi:10.1016/j.nimb.2011.04.017.

${ }^{12}$ K. F. von Reden, M. L. Roberts, C. P. McIntyre, J. R. Burton, Nucl. Instrum. and Methods in Phys. Res. B (2011), in press, doi:10.1016/j.nimb.2011.04.019.

${ }^{13}$ J. E. Boers, Code PBGUNS 5.04 (2001), FAR-TECH Inc., 10350 Science Center Drive Building 14, Suite 150 San Diego, CA 92121-1136, http://www.far-tech.com/pbguns/index.html.

${ }^{14}$ G.A. and W.B. Herrmannsfeldt, R. and J.G. Becker, O. Kester, B. Zipfel, Code IGUN, Electron Optics Simulations, 451, Patrick Way, Los Altos, CA 94022, USA.

${ }^{15}$ A. Patel, J. S. Wills and W. T. Diamond, Rev. Sci. Instrum. 79, 043304-6 (2008).

${ }^{16}$ G. Alton and H. Bilheux, Rev. Sci. Instrum. 75, 1431-5 (2004). 